\title{
PD39 - Application of population pharmacokinetic modeling and simulation in the design of the optimal dose regime of rupatadine in children 2-5 year old children
}

\author{
Marta Valle ${ }^{1 *}$, Javier Estevez ${ }^{1}$, Lisa Charlotte Martial ${ }^{1}$, Eva Santamaria ${ }^{2}$, Iñaki Izquierdo ${ }^{2}$ \\ From 3rd Pediatric Allergy and Asthma Meeting (PAAM) \\ Athens, Greece. 17-19 October 2013
}

\section{Background}

Rupatadine is a second generation antihistamine $\mathrm{H} 1$ and antagonist of PAF for the treatment of allergic rhinitis and urticaria for which a new pediatric oral solution is now available for children between 6-11 y/o.

\section{Objectives}

1) To optimize the dose regime in children between 2 to 5 y/o old to reach similar plasma concentrations to children of 6-11 y/o with allergic rhinitis.

2) To build a new population pharmacokinetic (popPK) model in children including all ages (2-11 y/o) to evaluate if the proposed regimen, as a function of weight, is adequate to reach rupatadine exposure similar to adults and $\geq 12 \mathrm{y} / \mathrm{o}$.

\section{Methods}

A popPK model was developed, using data from 6-11 y/o study (STD I) including 11 patients with full PK profile in allergic rhinitis. A second study (STD2) including 2-5 y/o was optimal designed based on the parameters estimated from STD I, assuming: inclusion of $<40$ children, $<5$ samples per child in the shortest time window. A final popPK model was built for children 2-11 years. Influence of different covariates on model parameters was also evaluated. PopPK modeling and simulation was performed in NONMEM and optimal design in WINPOP software.

'Sant Pau, Barcelona, Spain

Full list of author information is available at the end of the article

\section{Results}

The dose administered in STD II was $2.5 \mathrm{mg} / \mathrm{kg}$ (weight $10-25 \mathrm{~kg}$ ) or $5 \mathrm{mg} / \mathrm{kg}$ (weight $>25 \mathrm{~kg}$ ) and 3 samples per child were needed in a $2 \mathrm{~h}$ time window. A twocompartmental model with first-order absorption and elimination where clearance depends on weight fitted the data for 2-11 y/o children. Mean (SD) estimates of parameters obtained by noncompartmental analysis of the steady-state simulated plasma concentrations for both subsets of children were similar: Cmax, 2.54(1.26) vs $1.96(0.52) \mathrm{ng} / \mathrm{mL} ; \mathrm{AUC}, 10.74(3.09)$ vs $10.38(4.31)$ $\mathrm{ng} / \mathrm{mL} / \mathrm{h} ; \mathrm{t} 1 / 2,12.28(3.09)$ vs $15.94(4.09)$, for children 6-11 y/o and children 2-5 y/o, respectively.

\section{Conclusion}

A popPK model for rupatadine was used in the design of a new clinical study. Rupatadine clearance in children 2-11 years increases with age. The used range of doses in children provides similar exposure to rupatadine to that associated with efficacy and safety in adults and adolescents $\geq 12 \mathrm{y} / \mathrm{o}$.

\section{Authors' details \\ ${ }^{1}$ Sant Pau, Barcelona, Spain. ${ }^{2}$ Uriach, Barcelona, Spain.}

Published: 28 February 2014

doi:10.1186/2045-7022-4-S1-P39

Cite this article as: Valle et al:: PD39 - Application of population pharmacokinetic modeling and simulation in the design of the optimal dose regime of rupatadine in children 2-5 year old children. Clinical and Translational Allergy 2014 4(Suppl 1):P39. 